\title{
The Relationship between Task conflict and team learning: the critical role of psychological safety
}

\author{
Qin Yan ${ }^{\mathrm{a}}$, Chengzhi Feng ${ }^{\mathrm{b}}$ and Tiejun $\mathrm{Wu}^{\mathrm{c}}$. \\ Education School, Soochow University, Suzhou, China \\ aqinyan45@126.com, ${ }^{\text {b }}$ psyfeng@gmail.com, ${ }^{\text {c* } y o u r s t u d e n t @ 163 . c o m ~}$
}

\section{Keywords: Teams; Task Conflict; Team Learning; Psychological Safety}

\begin{abstract}
In an increasingly competitive workplace, the ability to learn from each other is quite critical. Past research has shown that team learning is one of the most important variables to promote team performance. This study describes the relationship between task conflict and team learning, and explores the moderate effect of psychological safety in the relationship. We selected 238 members in 72 self-management teams as participants, and invited them to finish questionnaires. The results indicated that task conflict exerted a negative effect on team learning. Additionally, relationship between task conflict and team learning was moderated by psychological safety. This study implies that task conflict may decline information processing effectiveness, and then showed negative effect on team learning. Besides, it would be useful to integrate psychological safety as one of the design factors which could foster successful team learning.
\end{abstract}

\section{Introduction}

In order to improve performance in the ever-changing marketplace, more and more organizations established work teams, and regarded teams as basic work units [1,2]. Although teamwork is quite popular nowadays, the challenges of working effectively in teams are still considerable [3]. How to deal with conflict is one of these tough challenges.

Past research has shown the importance of team structures and team design for enabling team effectiveness [4]; however, less is known about conditions enabling team learning. Thus, this research examines learning-oriented behaviors in self-management teams. The focus of the investigation is on task conflict and its effect on team learning.

Former studies have divided conflict into two aspects: task conflict and relationship conflict [5]. Empirical studies have shown that relationship conflict would reduce team outcomes, whereas the effect of task conflict is uncertain. Task conflict can improve team outcomes under some certain conditions but decreases team performance in others. To understand these conditions, researchers have proposed a number of factors that might facilitate performance from task conflict: characteristics of the conflict (e.g., type and level), characteristics of the team (e.g., psychological safety and conflict management) and characteristics of the task (e.g., interdependence and routineness) [6]. Whereas most studies have empirically demonstrated the characteristics of the conflict, the task and the team, investigations about the circumstance under which task conflict associated with team performance is rare [5]. This study tries to describe the relationship between task conflict and team learning, and discuss psychological safety as a potential moderator in this relationship.

\section{Hypothesis Development}

Task Conflict and Team Learning. Task conflict is one of the most important interactional dynamics in the teams [1]. It refers to disagreement among team members in decision-making and differences in viewpoints, ideas, and opinions about team tasks [7, 8]. As high quality of interaction is extremely essential for team learning [9], the author assumes that task conflict is closely related to team learning. Research shows that task conflict can promote sharing of knowledge in teams [10], 
trigger greater information exchange, revaluation of the status quo, and scrutiny of the task at hand $[11,12]$. Besides, it can also enhance the assessment process for the alternative proposals [13], and improve strategic decision-making [14].

Hypothesis 1: Task conflict is positively related to team learning.

The Moderating Role of Psychological Safety. Research shows that psychological safety may be one condition that alters the way conflict is received and managed in a team [3]. Psychological safety is a shared belief held by team members that the team is safe for interpersonal risk taking. In a team with high level of psychological safety, team members have the confidence that they would not be embarrassed, rejected, or punished when they speak up [15]. Also, they may feel comfortable to challenge others' ideas. Besides, they have a sense of openness and may put forward more ideas and discuss the team`s processes as team members have more time to solve problems and less time is spent on personal relations. Edmondson found that psychological safety positively related to learning behavior, suggestion that teams with a psychological safety learn more and performance better.

When the level of psychological safety is low, team members may be reluctant to share ideas or thoughts with others in order to protect themselves. This kind of climate may restrict team members participation and may lead to the lack of information exchange [15], fewer ideas and creative suggestions being shared. Then, sharing activities and learning behaviors were significantly declined.

Hypothesis 2: Psychological safety moderates the relationship between task conflict and team learning.

The research hypotheses are shown in Figure 1.

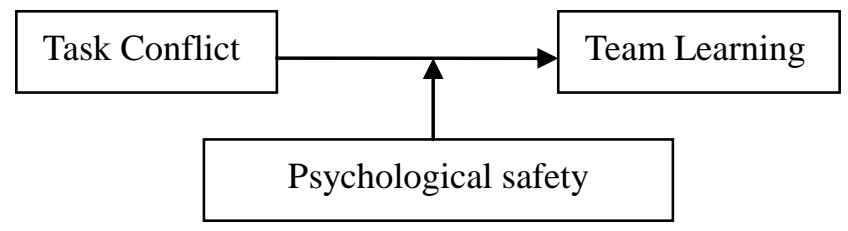

Figure. 1 Research hypotheses

\section{Method}

Procedures and Samples. We selected 238 individual members in 72 self-management teams as participants. All teams have been established more than 6 months at that time, and they were project teams which were asked to finish a project through co-operation in team members. Individual participants were invited to finish questionnaires in mid-March 2014. Three trained students helped participants to finish questionnaires, and took questionnaires back after completion. We got 241 valid individual data and the valid rate is $98.8 \%$.

\section{Instruments}

Task conflict questionnaire. Questionnaire developed by Jehn was used to assess task conflict level[1]. The questionnaire consists of 3 items, and items are measured in Likert 7 point scale. Cronbach alpha was 0.84

Psychological safety questionnaire. Questionnaire developed by West and Anderson was used to assess psychological safety [16]. The questionnaire consists of 5 items, and items are measured in Likert 5 point scale. Cronbach alpha was 0.92 .

Team learning questionnaire. Questionnaire developed by Edmondson was used to assess team learning [9]. The questionnaire consists of 7 items, and items are measured in Likert 7 points scale. Cronbach alpha was 0.88 .

Control variables. Team size refers to the number of teams members in a team. In this paper, it 
was controlled because researchers found that the size of the team influenced team processing [17].

\section{Results}

Transition from individual-level data to team level data. Use Rwg, ICC(1) and ICC(2) to check whether research data was team level data. Results showed that all variables were in team level. So, individual level data were converted into team level data by calculating means of team members' scores and using these means as team scores.

Hypotheses testing. Data was imported into the computer and analyzed by SPSS 16.0. Table 1 presents means, SD, and correlations matrix of the variables.

We used moderated hierarchical regression and simple slopes analysis to test hypotheses. The predictor variables were mean-centered, and the criterion variable was standardized using a $z$ score to improve graph interpretability.

The main effect of task conflict $(\beta=-.54, p<.01)$ was significant, explained 26 percent of variable in team learning, but the relationship between task conflict and team learning was negative. Hypothesis 1 was not supported.

Entered the product term for the interaction between task conflict and psychological safety, and examined the change in variance explained $\left(\Delta R^{2}\right)$ to assess the interaction. The interaction term was significant $\left(\Delta R^{2}=.07, p<.01\right)$. Hypothesis 2 was supported.

Table 1 Means, Standard Deviations, Correlations, and Scale Reliabilities among Variables

\begin{tabular}{lllllll}
\hline Variable & Mean & SD & 1 & 2 & 3 & 4 \\
\hline 1.team size & 3.32 & 1.44 & - & & & \\
2.task conflict & 3.08 & .76 & -.19 & $(.84)$ & & \\
3.psychological safety & 4.35 & .40 & .03 & $-.29^{*}$ & $(.92)$ & \\
4.team learning & 5.31 & .75 & .11 & $-.50^{* *}$ & $.56^{* *}$ & $(.88)$
\end{tabular}

Note. Cronbach's alpha appears along the diagonal in parentheses $(N=72$ teams $) . " ~ p<.05,{ }^{* * *} p<.01$.

\section{Discussion}

Results showed a negative relationship between task conflict and team learning. Hypothesis 1 was not supported by data. Here, several speculations were developed.

First, task conflict may decline information processing effectiveness, and then showed negative effect on team learning. According to the information-processing theory $[1,3]$, task conflict induces high level stress or tension, which does harm to information processing effectiveness. Actually, information processing is the core element of team learning. Second, people may not differentiate task and relationship conflict clearly; they regarded them as a whole. Some scholar noted that team members may not differentiate between task-related opinions and interpersonal bickering [18]. A recent meta- analytic evidence showed that correlation between task conflict and relationship conflict was up to 0.58 , which means that they are highly correlated [19]. So, negative effect of relationship on team outcome may spread to task conflict.

This research also implies that psychological safety can alter the way task conflict is received and managed in teams. When teams develop a climate where teammates feel secure sharing ideas with each other, it may reduce the negative relationship of task conflict on team learning.

\section{Acknowledgment}

This research was supported by National Social Science Fund(No. 12CGL050), and Jiangsu University Philosophy and Social Science Research Fund of Education Department, Jiangsu 
Province(No.2012SJB190012)

\section{References}

[1] E. A. Mannix and K. A. Jehn: Academy of Management Journal, Vol. 44 (2001), p.238

[2] K. Konstantinos and N. Bozionelos: Group \& Organization Management, Vol. 36 (2011) No.3, p.385

[3] C. K. W. De Dreu and L. R. Weingart: Journal of Applied Psychology, Vol. 88 (2003b), p.741

[4] A. M. Edmondson: Group and Organizational Influences on Team Learning. (Ph. D, Harvard University, America 1996). P.6

[5] B. H. Bradley, B. E. Postlethwaite, A. C. Klotz, M. R. Hamdani and K. G. Brown: Journal of Applied Psychology, Vol. 97 (2012) No.1, p.151

[6] B H. Bradley, A. C. Klotz, B. E. Postlethwaite and K. G. Brown: Journal of Applied Psychology, Vol. 98 (2013) No.2, p.385

[7] K. A. Jehn: Administrative Science Quarterly, Vol. 40 (1995), p.256

[8] T. L.Simons, and R. S. Peterson: Journal of Applied Psychology, Vol. 85 (2000), p.102

[9] A. Rowe: Management Learning, Vol. 39 (2008) No.1, p.41

[10]N.Panteli and S. Sockalingam: Decision Support Systems, Vol. 39 (2005), p.599

[11] U. R. Hulsheger, N. Anderson and J. F. Salgado: Journal of Applied Psychology, Vol. 94 (2004), p. 1128

[12]C. E.Shalley, J. Zhou, and G. R. Oldham: Journal of Management, Vol. 6 (2004), p. 933

[13]R. Baron: Journal of Applied Psychology, Vol. 69 (1984), p.272

[14]J.L. Farh, C. Lee and C. I. Farsh: Journal of Applied Psychology, Vol. 95 (2010) No.6, p.1173

[15]A. C. Edmondson: Administrative Science quarterly, Vol. 44 (1999) No.2, p.350

[16]M. A. West and N. R. Anderson: Journal of Applied Psychology, Vol. 81 (1996), p.680

[17]M. K. Duffy, J. D. Shaw and E. M. Stark: Academy of Management Journal, Vol. 43 (2000), p.772

[18]J. D. Shaw, J. Zhu, M. K. Duffy \& K. L. Scott, H. Shih and E. Susanto: Journal of Applied Psychology, Vol. 96 (2011) No. 2, p.391

[19]F. R. C. de Wit, L. L. Greer and K. A. Jehn: Journal of Applied Psychology. Vol. 97 (2012), p.360 